\title{
Neoadjuvant or Adjuvant Chemotherapy Plus Concurrent CRT Versus Concurrent CRT Alone in the Treatment of Nasopharyngeal Carcinoma: A Study Based on EBV DNA
}

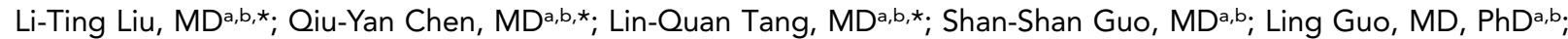

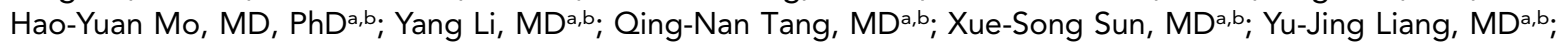
Chong Zhao, MD, PhD ${ }^{a, b}$; Xiang Guo, MD, PhD a,b; Chao-Nan Qian, MD, PhD ${ }^{a, b}$; Mu-Sheng Zeng, PhD ${ }^{a}$; Jin-Xin Bei, PhDa; Ming-Huang Hong, MD, PhD ${ }^{a, c}$; Jian-Yong Shao, MD, PhD a,d; Ying Sun, MD, PhD ${ }^{a, e}$;
\end{abstract} Jun $\mathrm{Ma}, \mathrm{MD}, \mathrm{PhD}^{\mathrm{a}, \mathrm{e}}$; and Hai-Qiang Mai, MD, $\mathrm{PhD}^{\mathrm{a}, \mathrm{b}}$

\begin{abstract}
Background: The goal of this study was to explore the value of adding neoadjuvant chemotherapy (NACT) or adjuvant chemotherapy (ACT) to concurrent chemoradiotherapy (CCRT) in patients with nasopharyngeal carcinoma (NPC) with different risks of treatment failure. Patients and Methods: A total of 2,263 eligible patients with stage III-IVb NPC treated with CCRT \pm NACT or ACT were included in this retrospective study. Distant metastasis-free survival (DMFS), overall survival, and progression-free survival were calculated using the Kaplan-Meier method and differences were compared using the log-rank test. Results: Patients in the low-risk group (stage N0-1 disease and Epstein-Barr virus [EBV] DNA $<4,000$ copies $/ \mathrm{mL}$ ) who received NACT followed by CCRT achieved significantly better 5-year DMFS than those treated with CCRT alone (96.2\% vs $91.3 \% ; P=.008$ ). Multivariate analyses also demonstrated that additional NACT was the only independent prognostic factor for DMFS (hazard ratio, 0.42; $95 \% \mathrm{Cl}, 0.22-0.80 ; P=.009)$. In both the intermediate-risk group (stage N0-1 disease and EBV DNA $\geq 4,000$ copies $/ \mathrm{mL}$ and stage N2-3 disease and EBV DNA $<4,000$ copies $/ \mathrm{mL}$ ) and the high-risk group (stage N2-3 disease and EBV DNA $\geq 4,000$ copies $/ \mathrm{mL}$ ), comparison of NACT or ACT + CCRT versus CCRT alone indicated no significantly better survival for all end points. Conclusions: The addition of NACT to CCRT could reduce distant failure in patients with low risk of treatment failure.
\end{abstract}

J Natl Compr Canc Netw 2019;17(6):703-710 doi: $10.6004 /$ jnccn.2018.7270

${ }^{\text {aS }}$ Sate Key Laboratory of Oncology in South China, Collaborative Innovation Center for Cancer Medicine, bepartment of Nasopharyngeal Carcinoma, ${ }^{\mathrm{C}}$ Good Clinical Practice Center, ${ }^{\mathrm{d} D e p a r t m e n t}$ of Molecular Diagnostics, and eDepartment of Radiation Oncology, Sun Yat-sen University Cancer Center, Guangzhou, People's Republic of China.

\section{Background}

Nasopharyngeal carcinoma (NPC), particularly the undifferentiated subtype, is prevalent in South Asia and South China. ${ }^{1,2}$ Radiotherapy (RT) is the mainstay treatment of NPC. With the innovation of modern imaging and radiation techniques, a high cure rate has been achieved for patients with early-stage NPC. However, due to its deep-seated location, $70 \%$ to $80 \%$ of patients are not diagnosed until the disease is at the advanced stage. ${ }^{3}$ For advanced-stage disease, RT in combination with concurrent chemotherapy has been shown to be the standard treatment protocol. ${ }^{4,5}$ Despite the use of concurrent chemotherapy, distant metastasis is still a major component of treatment failures, occurring in $18 \%$ to $27 \%$ of patients. ${ }^{5,6}$ To improve these results, additional systemic therapy has been explored, such as adding neoadjuvant or adjuvant chemotherapy (NACT or ACT, respectively) to concurrent chemoradiotherapy (CCRT).$^{7-12}$ However, due to inconsistent results of several prospective randomized trials, the additional benefit of adding NACT or ACT to CCRT remains controversial.

Currently, therapeutic decisions are based primarily on TNM stage. However, given tumor heterogeneity, patients with similar stages and histologic classifications have markedly different survival outcomes. Infection with Epstein-Barr virus (EBV) is strongly linked to NPC. ${ }^{13,14}$ Previous studies have shown that patients with high levels of pretreatment plasma EBV DNA have higher rates of distant relapse and death. ${ }^{15,16}$ Thus, plasma EBV

See JNCCN.org for supplemental online content.

*These authors contributed equally. 
DNA level, as a supplement to disease stage, could help to stratify patients into different groups of risk of treatment failure. Patients in the high-risk group might benefit from the addition of NACT or ACT to CCRT. The ongoing NRG-HN001 study (ClinicalTrials. gov identifier: NCT02135042) is using EBV DNA to risk-stratify patients and determine ACT; no previous studies have used plasma EBV DNA to select eligible treatment participants. The goal of our study was to compare patients in different risk groups who received different chemotherapy treatments to determine the optimal therapeutic strategy for individuals with NPC.

\section{Patients and Methods}

From January 2004 to December 2012, we identified 6,996 patients in our institute who were newly diagnosed with NPC. Eligibility criteria included (1) biopsy-proven WHO histopathologic type II or III NPC; (2) age $\geq 18$ years; (3) stages III-IVb disease according to the seventh edition of the International Union Against Cancer/AJCC TNM staging system; (4) ECOG performance status of 0 or 1 ; (5) treatment with intensity-modulated RT; (6) received CCRT \pm NACT or ACT; (7) complete data of pretreatment plasma EBV DNA level; and (8) adequate hematologic, liver, and renal function. Exclusion criteria included history of previous or synchronous malignant tumors, additional use of targeted therapy or immunotherapy, pregnancy or lactation, primary distant metastasis, and insufficient follow-up data. A total of 2,263 eligible patients were included in the study (Figure 1). This study was approved by Sun Yat-sen University Cancer Center's Clinical Research Committee.

\section{Pretreatment Evaluation}

All patients underwent a complete physical examination, fiberoptic nasopharyngoscopy, electrocardiography, MRI of the nasopharynx and neck, chest radiography, abdominal ultrasound, skeletal scintigraphy or whole-body fluorodeoxyglucose PET/CT, CBC count, biochemical profile, and EBV serology with plasma EBV DNA level.

\section{RT and Chemotherapy}

All patients were treated with concurrent cisplatin $\left(100 \mathrm{mg} / \mathrm{m}^{2}\right)$ at weeks 1,4 , and 7 of the RT cycle. Among them, 970 patients received CCRT alone, 1,073 received 2 or 3 cycles of NACT followed by CCRT, and 220 received CCRT followed by 1 to 4 cycles of adjuvant PF (cisplatin, $80 \mathrm{mg} / \mathrm{m}^{2}$ on day 1 with 5-fluorouracil, $800-1,000 \mathrm{mg} / \mathrm{m}^{2}$ for 96 hours of continuous intravenous infusion). ${ }^{17}$ The regimen of NACT included PF, TP (cisplatin with docetaxel, $75 \mathrm{mg} / \mathrm{m}^{2}$ on day 1 ), and TPF (cisplatin, $75 \mathrm{mg} / \mathrm{m}^{2}$ on day 1 and docetaxel, $75 \mathrm{mg} / \mathrm{m}^{2}$ on day 1 , with 5-fluorouracil, $750 \mathrm{mg} / \mathrm{m}^{2}$ for 96 hours of continuous

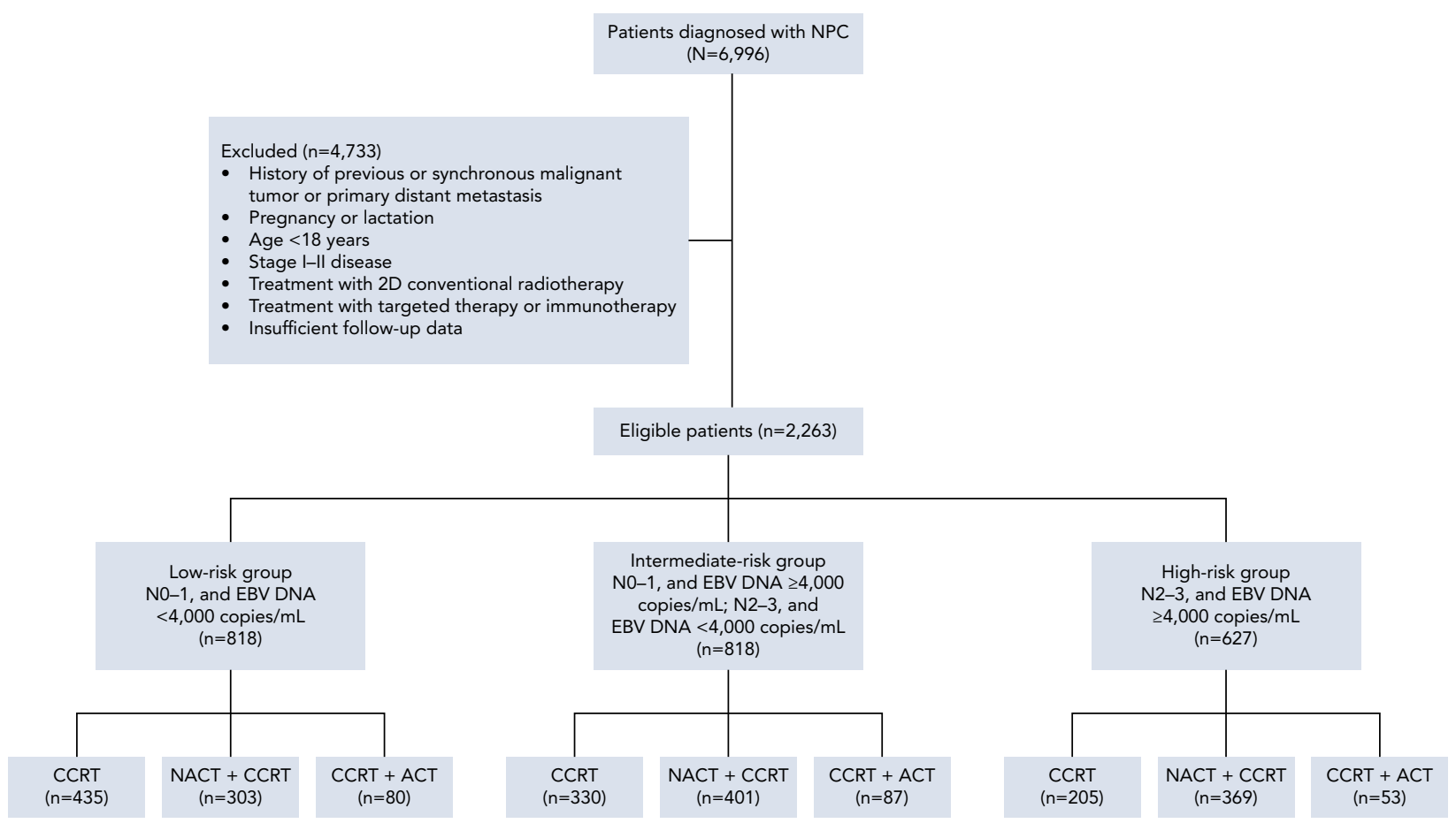

Figure 1. Flowchart of patients included in the study.

Abbreviations: ACT, adjuvant chemotherapy; CCRT, concurrent chemoradiotherapy; EBV, Epstein-Barr virus; NACT, neoadjuvant chemotherapy; NPC, nasopharyngeal carcinoma. 
intravenous infusion). ${ }^{7,9,18}$ The intensity-modulated RT plan was designed according to previous studies, and treatment followed the general design at our institute (supplemental eAppendix 1, available with this article at JNCCN.org). ${ }^{19,20}$

\section{Plasma EBV DNA-Level Assessment}

Plasma EBV DNA concentrations were measured with real-time quantitative PCR before treatment. ${ }^{21,22}$ Pretreatment EBV DNA levels were divided into a low and high group based on the cutoff value of 4,000 copies $/ \mathrm{mL}$, which was established as a prognostic value in previous studies. ${ }^{15,23}$

\section{Clinical Outcome and Follow-Up}

Our primary study end point was distant metastasis-free survival (DMFS), which was calculated from the first day of treatment to the date of distant metastasis. The secondary end point included overall survival (OS), which was calculated from the start of treatment to the date of death of any cause, and progression-free survival (PFS), which was calculated from the first day of treatment to the date of any treatment failure or death of any cause. Patients were censored if they were still alive on August 4, 2017, the date of last follow-up. After treatment, patients were examined at 3 -month intervals for the first 3 years and every 6 months thereafter or until death.

\section{Statistical Analysis}

Categorical variables were compared using the chisquare or Fisher exact test. The Kaplan-Meier method was used to estimate the cumulative survival rates, and survival curves were compared using the log-rank test. Hazard ratios (HRs) with 95\% CIs were calculated using the Cox proportional hazards model. Univariate and multivariate analyses using Cox proportional hazards models were performed to evaluate the independent significance of the treatment group (different timing of chemotherapy to CCRT) and other potential prognostic factors, including age, sex, tumor stage, history of NPC, early antigen immunoglobulin A, and viral capsid antigen immunoglobulin A. Tests were 2-sided, and a $P$ value $<.05$ was considered significant.

\section{Results}

The characteristics of the 2,263 patients in the different treatment groups are presented in Table 1. In the NACT + CCRT group ( $\mathrm{N}=1,073), 81.5 \%$ of patients $(\mathrm{n}=875)$ received 3 cycles and $18.5 \%(\mathrm{n}=198)$ received 2 cycles of NACT, and $45.5 \%(n=483)$ received 3 cycles and $55.0 \%(n=590)$ received 2 cycles of CCRT. In the CCRT + ACT group $(\mathrm{N}=220), 5.9 \%$ of patients $(\mathrm{n}=13)$ received 4 cycles, $31.4 \%(\mathrm{n}=69)$ received 3 cycles, $44.5 \%(n=98)$ received 2 cycles, and $18.2 \%(n=400)$ received 1 cycle of ACT, and $68.6 \%(\mathrm{n}=151)$ received 3 cycles and $31.4 \%(n=69)$ received 2 cycles of CCRT. In the CCRT group $(\mathrm{N}=970), 55.1 \%$ of patients $(\mathrm{n}=534)$ received 3 cycles of CCRT and $44.9 \%(n=436)$ received 2 cycles. For the entire cohort $(\mathrm{N}=2,263)$, within the median follow-up of 68 months (range, 3-128 months), $17.8 \%$ of patients $(n=403)$ died, $14.8 \%(n=335)$ developed distant metastasis, and 9.7\% ( $n=220)$ exhibited locoregional relapse. For all end points, significant survival curve separations were not observed among the 3 treatment groups (supplemental eTable 1, Figure 2). Significant survival benefit was not achieved with the addition of NACT or ACT to CCRT (supplemental eFigure 1). In addition, the survival curves of different chemotherapy regimens of NACT were not significantly segregated (supplemental eFigure 2). Therefore, we further analyzed the relationship between treatment method and clinical outcome in different risk groups.

\section{Risk Stratification}

As we reported earlier, ${ }^{24} \mathrm{~N}$ stage and pretreatment EBV DNA were significantly correlated with distant metastasis. Moreover, patients with N0-1 stage disease with high EBV DNA ( $\geq 4,000$ copies $/ \mathrm{mL}$ ) and those with N2-3 stage disease with low EBV DNA $(<4,000$ copies $/ \mathrm{mL})$ had similar likelihoods of developing distant metastasis. ${ }^{24}$ In this study, $6.6 \%$ of patients (54 of 818) with N0-1 disease and low EBV DNA exhibited distant metastasis, $14.4 \%$ (118 of 818) with N0-1 disease and high EBV DNA or N2-3 disease and low EBV DNA exhibited distant metastasis, and $26.0 \%$ (163 of 627) with N2-3 disease and high EBV DNA developed distant metastasis. Thus, eligible patients in our study were divided into 3 different risk groups: low-risk (N0-1 and low EBV DNA), intermediaterisk (N0-1 disease and high EBV DNA or N2-3 disease and low EBV DNA), and high-risk (N2-3 disease and high EBV DNA). Characteristics of patients treated with different methods in different risk groups are shown in supplemental eTable 2 . Survival curves were significantly segregated among patients in different risk groups for DMFS $(P<.001)$, OS $(P<.001)$, and PFS $(P<.001)$ (supplemental eFigure 3$)$.

\section{Relationship Between Treatment and Clinical Outcome in Low-Risk Group}

Patients who received NACT followed by CCRT achieved significantly better 5-year DMFS than those treated with CCRT alone (96.2\% vs 91.3\%; $P=.008$ ) (Table 2, eFigure 4. In multivariate analyses, additional NACT significantly reduced the risk of distant metastasis and was also the only independent prognostic factor for DMFS (HR, 0.42; 95\% CI, $0.22-0.80 ; P=.009$ ). Multivariate analyses also demonstrated that smoking was an independent prognostic factor for PFS (HR, 1.53; 95\% CI, 1.02-2.31; $P=.040$ ) (Table 3). 


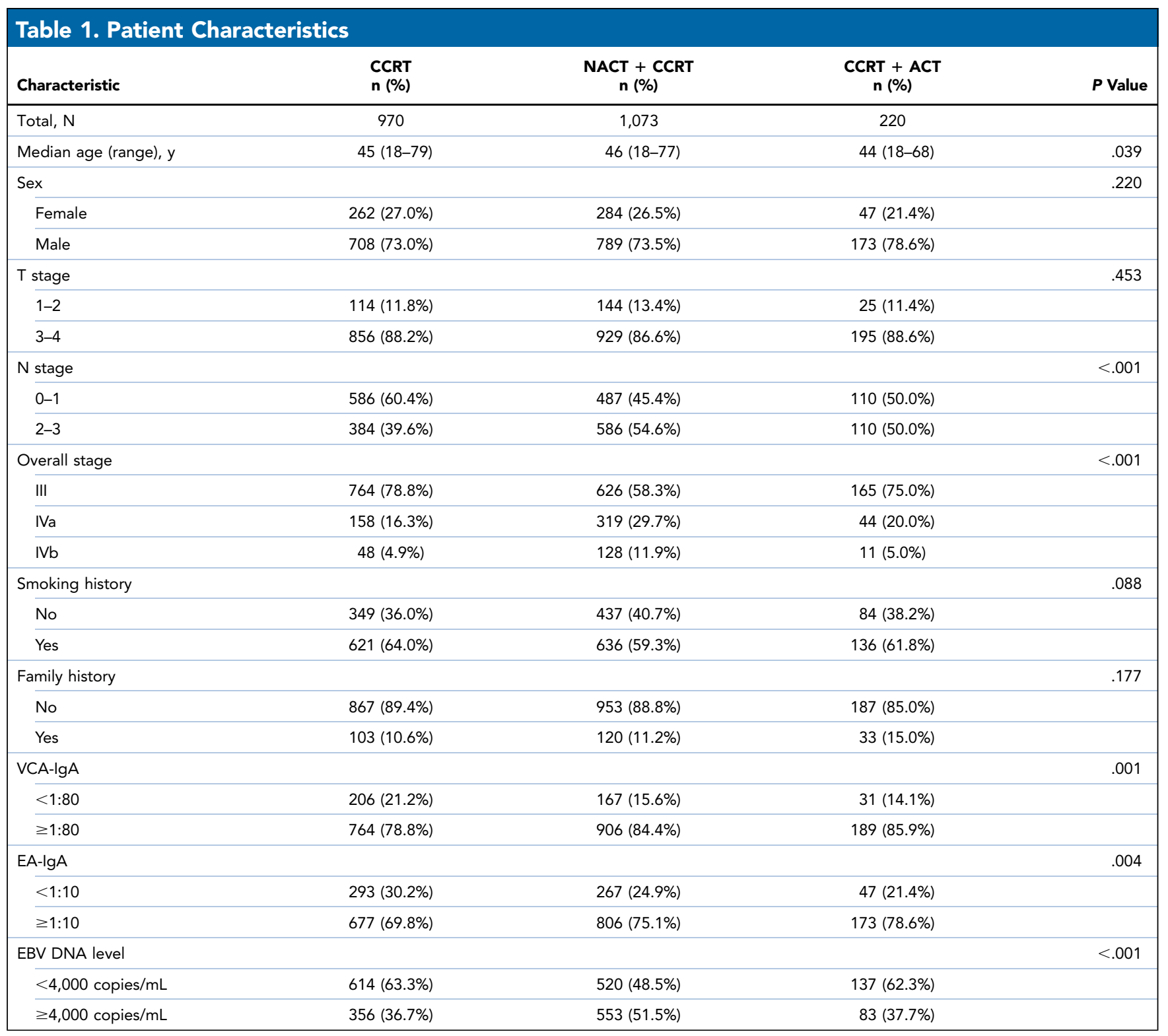

Abbreviations: $A C T$, adjuvant chemotherapy; CCRT, concurrent chemoradiotherapy; $E A$, early antigen; EBV, Epstein-Barr virus; IgA, immunoglobulin $A$; NACT, neoadjuvant chemotherapy; VCA, viral capsid antigen.

Relationship Between Treatment and Clinical

Outcome in Intermediate-Risk Group

Patients treated with NACT or ACT in addition to CCRT in the intermediate-risk group had no significantly better survival than those in the CCRT-alone group (Table 2). When adjusting for other factors at multivariate analysis, $\mathrm{T}$ stage was an independent prognostic factor for DMFS (HR, 2.17; 95\% CI, 1.13-4.17; $P=.020$ ), OS (HR, 2.17; 95\% CI, 1.20-3.93; $P=.011$ ), and PFS (HR, 2.12; 95\% CI, 1.31-3.46; $P=.002$ ) (Table 3). Sex was an independent prognostic factor for DMFS (HR, 2.06; 95\% CI, 1.21-3.51; $P=.008$ ) and OS (HR, 1.79; 95\% CI, 1.10-2.90; $P=.019$ ). However, the treatment group was not an independent prognostic factor for all end points.
Relationship Between Treatment and Clinical Outcome in High-Risk Group In the high-risk group, comparison of NACT or ACT + CCRT versus CCRT alone still indicated no significantly better survival (Table 2, eFigure 4). Multivariate analyses demonstrated that no prognostic factor was correlated with DMFS, OS, and PFS (Table 3).

\section{Discussion}

To our knowledge, the efficacy of systemic chemotherapy in addition to RT in patients with advanced-stage disease at different risk levels of distant metastasis was not well established in previous studies. Results of our study showed that NACT followed by CCRT could significantly 
A

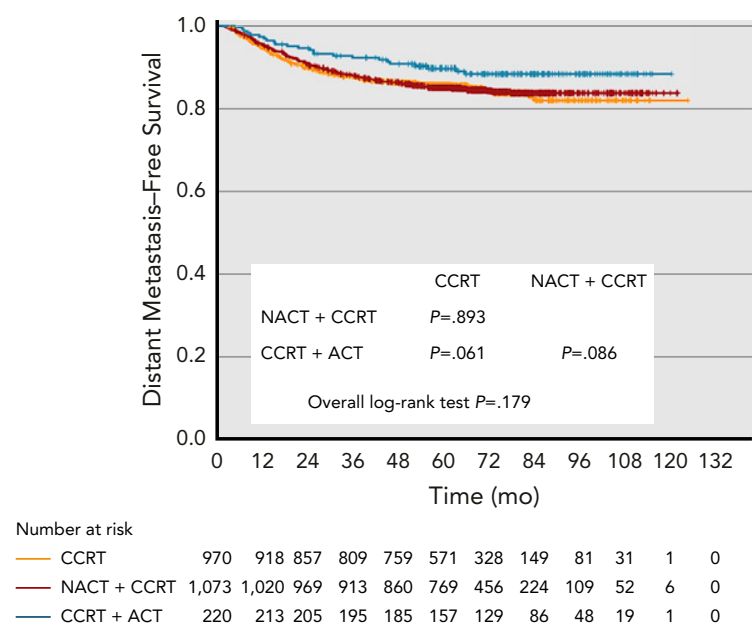

B

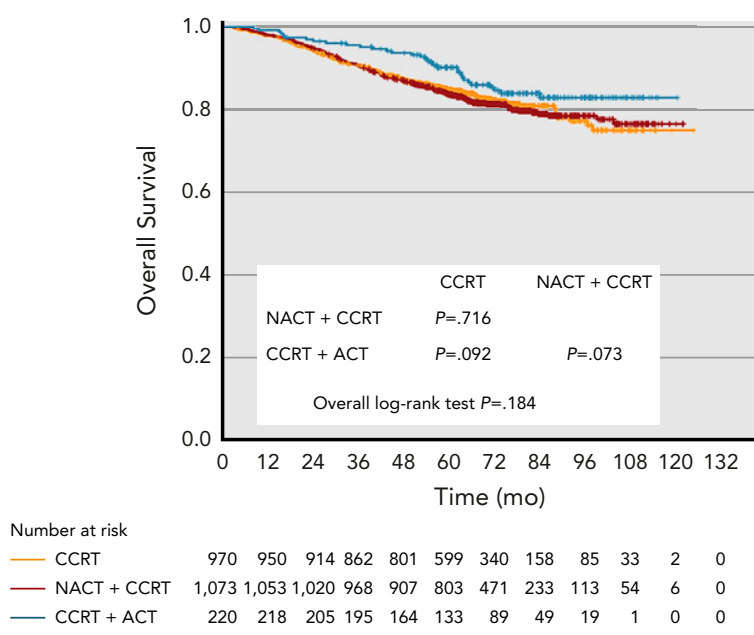

C

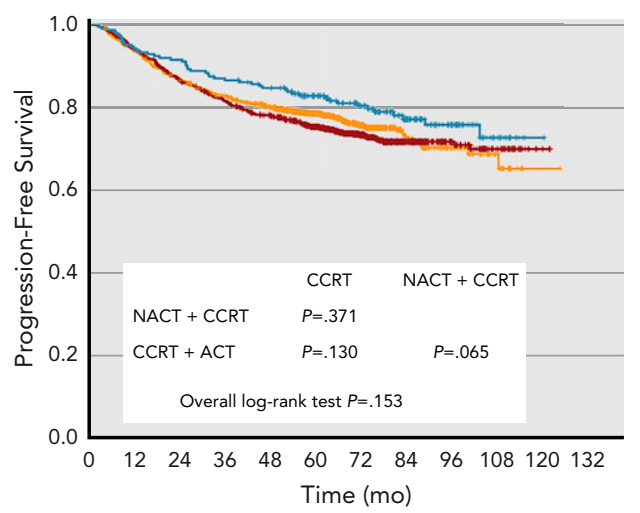

Number at risk

$\begin{array}{lllllllllllll}\text { C CCRT } & 970 & 913 & 843 & 785 & 731 & 548 & 311 & 142 & 76 & 30 & 1 & 0\end{array}$

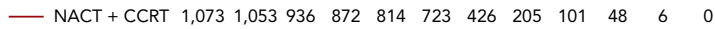

$\begin{array}{lllllllllllll}-\mathrm{CCRT}+\mathrm{ACT} & 220 & 209 & 201 & 190 & 181 & 154 & 128 & 85 & 47 & 18 & 1 & 0\end{array}$

Figure 2. Comparison of the probability of different treatment methods with regard to (A) distant metastasis-free survival, (B) overall survival, and (C) progression-free survival rates.

Abbreviations: ACT, adjuvant chemotherapy; CCRT, concurrent chemoradiotherapy; NACT, neoadjuvant chemotherapy. reduce the risk of distant metastasis compared with CCRT alone in patients in the low-risk group. However, no significant OS benefit was observed for either the addition of NACT or ACT.

Since the landmark Intergroup 0099 trial, ${ }^{17}$ studies concerning the interaction between the timing of chemotherapy and the effect on various end points have been ongoing. Several meta-analyses showed that the survival benefit primarily comes from the concurrent phase. ${ }^{5,25}$ Although high locoregional control rates are currently achieved with CCRT for advanced-stage NPC, distant metastasis has become the leading cause of treatment failure. ${ }^{5,6}$ Our study investigated the efficacy of NACT or ACT in addition to CCRT. The NCCN Clinical Practice Guidelines in Oncology (NCCN Guidelines) for Head and Neck Cancers recommend CCRT followed by ACT for stages II-IVb NPC, and this recommendation is supported by level IIA evidence. ${ }^{26}$ The combined analyses of the NPC-9901 and NPC-9902 trials also demonstrated that ACT contributed to improving distant control. ${ }^{27} \mathrm{~A}$ retrospective study by Twu et $\mathrm{al}^{28}$ showed that ACT could reduce distant failure and improve OS (71.6\% vs $28.7 \% ; P<.001)$ in patients with persistently detectable EBV DNA after CCRT. However, the phase III trial by Chen et $\mathrm{al}^{29}$ showed no statistically significant improvement in failure-free survival with additional ACT. Notably, compliance with ACT is poor. In previous studies, only $52 \%$ to $61 \%$ of patients completed 3 cycles of ACT, and half of these had dose reductions. ${ }^{17,29-32}$ Theoretically, changing to NACT might improve tolerance and early eradication of potent micrometastases. Therefore, NACT followed by CCRT became the research focus. In 2009, a phase II trial conducted by Hui et $\mathrm{al}^{5}$ reported that adding neoadjuvant cisplatin and docetaxel to CRT increased PFS by $28.7 \%$. Another phase II trial by Fountzilas et $\mathrm{al}^{8}$ and a phase II/III trial by Tan et $\mathrm{al}^{12}$ both failed to show a significant survival benefit at 3 years. Preliminary results of the NPC-0501 trial indicated that the benefit of changing to an inductionconcurrent sequence remains uncertain. ${ }^{9}$ However, Sun et $\mathrm{al}^{33}$ more recently reported that NACT + CCRT could improve survival outcomes in NPC. Thus, there are differing opinions regarding whether the addition of NACT or ACT to CCRT should be recommended.

In our study, analysis of all 2,263 patients failed to show a significant survival benefit among the 3 treatment groups. We believe one possible reason for these controversial results was the therapeutic decisions in the aforementioned studies, which were simply based on TNM stage. As reported previously, pretreatment plasma EBV DNA level significantly correlated with clinical outcome. Patients with high pretreatment EBV DNA levels were more likely to develop treatment failure, especially distant metastases. ${ }^{15,16,23} \mathrm{~N}$ stage also correlated with distant 


\begin{tabular}{|c|c|c|c|c|c|c|c|c|}
\hline & $\mathbf{n}$ & $\%$ & 5-Year DMFS $(95 \% \mathrm{Cl})$ & $P$ Value & 5-Year OS $(95 \% \mathrm{Cl})$ & $P$ Value & 5-Year PFS (95\% Cl) & $P$ Value \\
\hline Low-risk groupa & 818 & & & .021 & & .209 & & .743 \\
\hline CCRT & 435 & 53.2 & $91.3 \%(88.6 \%-94.0 \%)$ & & $91.6 \%(88.9 \%-94.3 \%)$ & & $85.8 \%(82.5 \%-89.2 \%)$ & \\
\hline NACT + CCRT & 303 & 37.0 & $96.2 \%(94.0 \%-98.4 \%)$ & & $93.3 \%$ (90.4\%-96.2\%) & & $85.2 \%(81.1 \%-89.3 \%)$ & \\
\hline CCRT + ACT & 80 & 9.8 & $94.7 \%(89.6 \%-99.8 \%)$ & & $94.5 \%(89.2 \%-99.8 \%)$ & & $88.3 \%(81.0 \%-95.6 \%)$ & \\
\hline Intermediate-risk group ${ }^{\mathrm{b}}$ & 818 & & & .805 & & .475 & & 233 \\
\hline CCRT & 330 & 40.3 & $87.3 \%(83.6 \%-91.0 \%)$ & & $85.5 \%$ (79.8\%-91.3\%) & & $79.1 \%(74.6 \%-83.6 \%)$ & \\
\hline NACT + CCRT & 401 & 49.0 & $85.8 \%(82.3 \%-89.3 \%)$ & & $83.3 \%$ (79.6\%-87.0\%) & & $74.8 \%(77.6 \%-92.4 \%)$ & \\
\hline CCRT + ACT & 87 & 10.6 & $89.4 \%(82.9 \%-95.9 \%)$ & & $91.2 \%(84.9 \%-97.5 \%)$ & & $85.0 \%(83.6 \%-91.0 \%)$ & \\
\hline High-risk groupc & 627 & & & .102 & & .128 & & .117 \\
\hline CCRT & 205 & 32.7 & $70.2 \%(63.7 \%-76.7 \%)$ & & $69.4 \%$ (62.9\%-75.9\%) & & $60.9 \%(54.2 \%-67.6 \%)$ & \\
\hline NACT + CCRT & 369 & 58.9 & $75.2 \%(70.7 \%-79.7 \%)$ & & $76.8 \%(72.5 \%-81.1 \%)$ & & $66.9 \%(62.0 \%-71.8 \%)$ & \\
\hline $\mathrm{CCRT}+\mathrm{ACT}$ & 53 & 8.5 & $82.4 \%(72.0 \%-92.8 \%)$ & & $74.1 \%(61.9 \%-86.3 \%)$ & & $67.7 \%(55.0 \%-80.4 \%)$ & \\
\hline
\end{tabular}

Abbreviations: ACT, adjuvant chemotherapy; CCRT, concurrent chemoradiotherapy; DMFS, distant metastasis-free survival; EBV, Epstein-Barr virus; NACT, neoadjuvant chemotherapy; OS, overall survival; PFS, progression-free survival.

aLow-risk group: stage N0-1 disease and EBV DNA $<4,000$ copies $/ \mathrm{mL}$.

'Intermediate-risk group: stage N0-1 disease and EBV DNA $\geq 4,000 \mathrm{copies} / \mathrm{mL}$ or stage N2-3 disease and EBV DNA <4,000 copies/mL.

'High-risk group: stage N2-3 disease and EBV DNA $\geq 4,000$ copies $/ \mathrm{mL}$.

metastasis. ${ }^{19}$ Therefore, taking these 2 factors into consideration, patients in our study were divided into 3 different risk groups. We further explored the efficacy of adding NACT and ACT to CCRT in patients with different risk levels. Interestingly, we found that patients in the lowrisk group (N0-1 disease and EBV DNA $<4,000$ copies/mL) achieved significantly better DMFS from NACT + CCRT than from CCRT alone. Furthermore, NACT + CCRT was the only independent prognostic factor for DMFS. Similarly, the trial by Sun et $\mathrm{al}^{33}$ also demonstrated a significant reduction in distant metastases in patients with N1 disease but not in those with $\mathrm{N} 2-3 \mathrm{~b}$ disease. The possible reason for these results is that patients with N2-3 or EBV DNA $\geq 4,000$ copies/ $\mathrm{mL}$ might have already had distant metastasis that could not be detected by imaging examination. In this case, an additional 2 or 3 cycles of NACT might not be enough to eradicate the metastasis. Therefore, a significant reduction in distant metastasis was not observed in these patients. The results could provide the basis for a trial that addresses additional NACT or ACT in the low-risk group.

In our study, patients in the high-risk group treated with CCRT + ACT experienced relatively higher DMFS rates than those treated with CCRT alone $(82.4 \%$ vs $70.2 \%)$. This result was in line with findings of a recent meta-analysis conducted by Ribassin-Majed et al. ${ }^{34}$ However, survival rates in our study failed to show significant differences between the 2 groups. Compliance with ACT and the small sample size of patients treated with ACT could potentially affect treatment outcome. In the high-risk group, only 53 patients underwent ACT, which underpowered the results. Furthermore, among them, $69.8 \%$ of patients (37 of 53) received only 1 to 2 cycles of $\mathrm{ACT}$ and had dose reductions, and therefore improvement in survival benefit was inevitably hampered by the suboptimal treatment intensity. Therefore, giving combinations of new drugs with low toxicities to improve compliance with ACT might result in further improvements in survival.

In addition, multivariate analyses showed that male patients had poorer prognosis than their female counterparts in the intermediate-risk group, suggesting that a biologic difference in tumor behavior might exist between male and female patients in this group. The sex difference in prognosis might be due to genetic variants, inappropriate diet, environmental tobacco smoke, and occupational exposures to formaldehyde and dusts in the intermediate-risk group. ${ }^{35-37}$ Future studies on the mechanisms of sex differences in NPC progression are needed.

Our study has several limitations. First, this was a retrospective study in a single center; therefore, results must be validated by other datasets and prospective studies. Second, only 220 patients in our study received CCRT + ACT; thus, the sample size in each risk group was relatively small. A larger sample size of patients treated with CCRT + ACT is needed to evaluate the long-term outcomes of these patients. Finally, the lack of integrated toxicity data for different treatment methods makes these results underpowered. In the future, a well-designed, multicenter, prospective, randomized study is needed to validate our results.

\section{Conclusions}

Our study demonstrated that patients with NPC in the low-risk group who were treated with NACT + CCRT had significantly reduced hazards of distant metastasis compared with patients treated with CCRT alone. 
Table 3. Multivariate Analyses of Potential Prognostic Factors in Clinical Outcomes

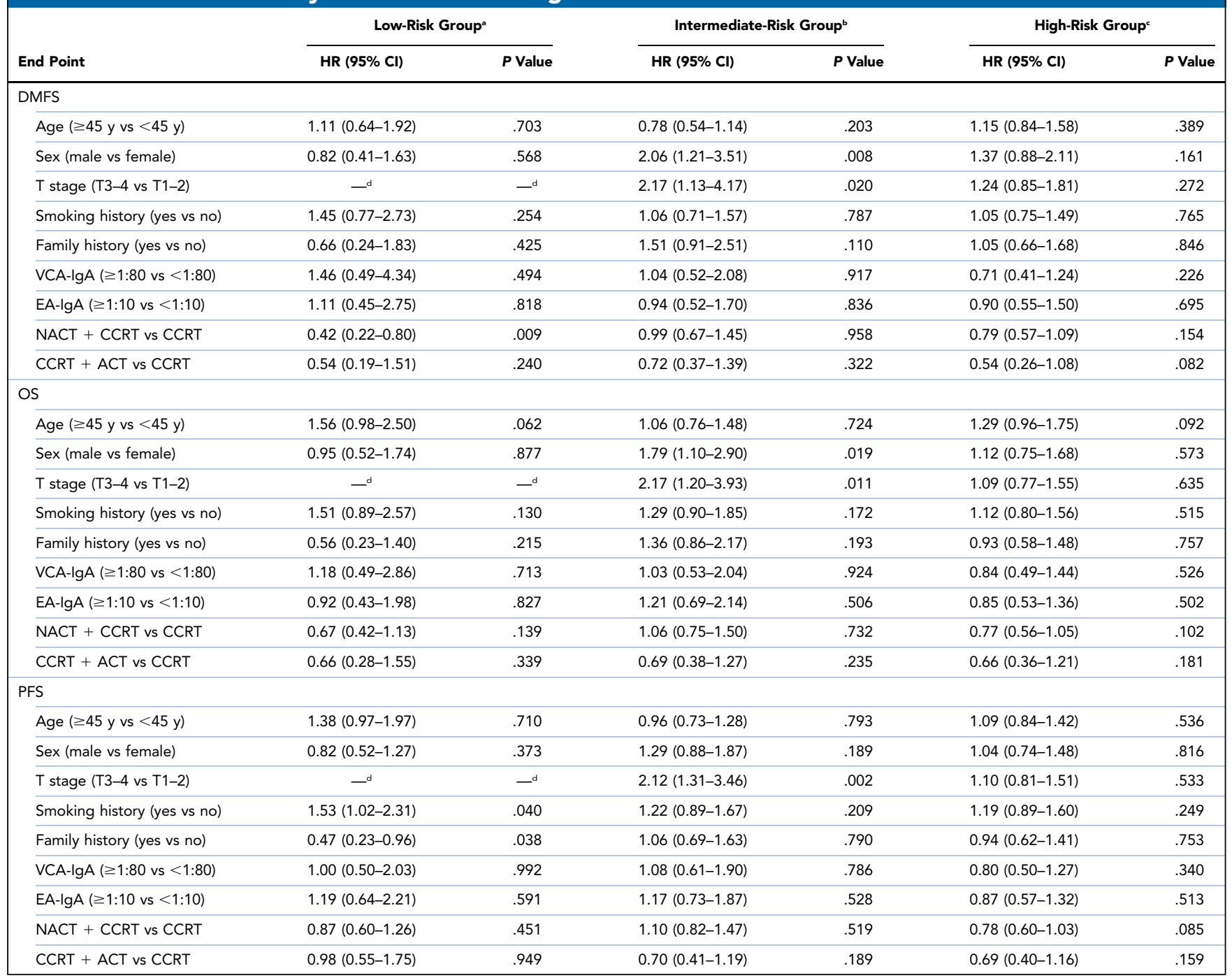

Abbreviations: ACT, adjuvant chemotherapy; CCRT, concurrent chemoradiotherapy; DMFS, distant metastasis-free survival; EA, early antigen; EBV, Epstein-Barr virus; HR, hazard ratio; IgA, immunoglobulin $A$; NACT, neoadjuvant chemotherapy; OS, overall survival; PFS, progression-free survival; VCA, viral capsid antigen. aLow-risk group: stage N0-1 disease and EBV DNA $<4,000$ copies $/ \mathrm{mL}$.

bIntermediate-risk group: stage N0-1 disease and EBV DNA $\geq 4,000$ copies $/ \mathrm{mL}$ or stage N2-3 disease and EBV DNA $<4,000 \mathrm{copies} / \mathrm{mL}$.

cHigh-risk group: stage N2-3 disease and EBV DNA $\geq 4,000$ copies $/ \mathrm{mL}$.

In low-risk group, all patients have stage T3-4 disease.

Disappointingly, the addition of NACT or ACT failed to achieve OS benefit. Future results of the ongoing NRG-HN001 study using EBV DNA to risk-stratify patients might provide more information on individualized treatment of NPC. Further investigation is necessary to confirm our findings.

Submitted August 26, 2018; accepted for publication January 7, 2019.

Author contributions: Study concept: Mai. Study design: Liu, Mai. Data acquisition: Liu, Chen, L.Q. Tang. Quality control of data and algorithms: Liu, Chen, L.Q. Tang, Mai. Data analysis and interpretation: Liu. Statistical analysis: Liu, Chen. Manuscript preparation: Liu, Chen, L.Q. Tang, S.S. Guo. Manuscript editing: Liu, Chen, L.Q. Tang, S.S. Guo, L. Guo, Mo. Manuscript review: Liu, Chen, L.Q. Tang, Zhao, X. Guo, Li, Qian, Zeng, Bei, Liang, Q.N. Tang, Hong, Shao, Sun, Ma, Mai.
Disclosures: The authors have not received any financial consideration from any person or organization to support the preparation, analysis, results, or discussion of this article.

Funding: Supported by grants from the National Key R\&D Program of China (2016YFC0902003, 2017YFC1309003, 2017YFC0908500), the National Natural Science Foundation of China $(81425018,81672868,81602371)$, the Sun Yat-sen University Clinical Research 5010 Program, the Sci-Tech Project Foundation of Guangzhou City (201707020039), the National Key Basic Research Program of China (2013CB910304), the Special Support Plan of Guangdong Province (2014TX01R145), the Sci-Tech Project Foundation of Guangdong Province (2014A020212103), the Health \& Medical Collaborative Innovation Project of Guangzhou City (201400000001), the National Science \& Technology Pillar Program during the Twelfth Five-year Plan Period (2014BAI09B10), the PhD Start-up Fund of Natural Science Foundation of Guangdong Province, China (2016A030310221), the cultivation foundation for the junior teachers in Sun Yat-Sen University (16ykpy28), and the Fundamental Research Funds for the Central Universities.

Correspondence: Hai-Qiang Mai, MD, PhD, Department of Nasopharyngeal Carcinoma, Sun Yat-sen University Cancer Center, 651 Dongfeng Road East, Guangzhou 510060, China. Email: maihq@sysucc.org.cn 


\section{References}

1. Cao SM, Simons MJ, Qian CN. The prevalence and prevention of nasopharyngeal carcinoma in China. Chin J Cancer 2011;30:114-119.

2. Choa G. Nasopharyngeal carcinoma: some observations on the clinical features and technique of examination. Pac Med Surg 1967;75:172-174.

3. Mao YP, Xie FY, Liu LZ, et al. Re-evaluation of 6th edition of AJCC staging system for nasopharyngeal carcinoma and proposed improvement based on magnetic resonance imaging. Int J Radiat Oncol Biol Phys 2009;73: 1326-1334.

4. Chan AT, Teo PM, Ngan RK, et al. Concurrent chemotherapyradiotherapy compared with radiotherapy alone in locoregionally advanced nasopharyngeal carcinoma: progression-free survival analysis of a phase III randomized trial. J Clin Oncol 2002;20:2038-2044.

5. Langendijk JA, Leemans CR, Buter J, et al. The additional value of chemotherapy to radiotherapy in locally advanced nasopharyngeal carcinoma: a meta-analysis of the published literature. J Clin Oncol 2004;22: 4604-4612.

6. Geara FB, Sanguineti G, Tucker SL, et al. Carcinoma of the nasopharynx treated by radiotherapy alone: determinants of distant metastasis and survival. Radiother Oncol 1997;43:53-61.

7. Hui EP, Ma BB, Leung SF, et al. Randomized phase II trial of concurrent cisplatin-radiotherapy with or without neoadjuvant docetaxel and cisplatin in advanced nasopharyngeal carcinoma. J Clin Oncol 2009;27: 242-249.

8. Fountzilas G, Ciuleanu E, Bobos M, et al. Induction chemotherapy followed by concomitant radiotherapy and weekly cisplatin versus the same concomitant chemoradiotherapy in patients with nasopharyngeal carcinoma: a randomized phase II study conducted by the Hellenic Cooperative Oncology Group (HeCOG) with biomarker evaluation. Ann Oncol 2012;23:427-435.

9. Lee AW, Ngan RK, Tung SY, et al. Preliminary results of trial NPC-0501 evaluating the therapeutic gain by changing from concurrent-adjuvant to induction-concurrent chemoradiotherapy, changing from fluorouracil to capecitabine, and changing from conventional to accelerated radiotherapy fractionation in patients with locoregionally advanced nasopharyngeal carcinoma. Cancer 2015;121:1328-1338.

10. Lee AW, Lau WH, Tung SY, et al. Preliminary results of a randomized study on therapeutic gain by concurrent chemotherapy for regionallyadvanced nasopharyngeal carcinoma: NPC-9901 Trial by the Hong Kong Nasopharyngeal Cancer Study Group. J Clin Oncol 2005;23: 6966-6975

11. Lee AW, Tung SY, Chan AT, et al. Preliminary results of a randomized study (NPC-9902 Trial) on therapeutic gain by concurrent chemotherapy and/or accelerated fractionation for locally advanced nasopharyngeal carcinoma. Int J Radiat Oncol Biol Phys 2006;66:142-151.

12. Tan T, Lim WT, Fong KW, et al. Concurrent chemo-radiation with or without induction gemcitabine, carboplatin, and paclitaxel: a randomized, phase $2 / 3$ trial in locally advanced nasopharyngeal carcinoma. Int J Radiat Oncol Biol Phys 2015;91:952-960.

13. Gulley ML. Molecular diagnosis of Epstein-Barr virus-related diseases. J Mol Diagn 2001;3:1-10.

14. Raab-Traub N. Epstein-Barr virus in the pathogenesis of NPC. Semin Cancer Biol 2002;12:431-441.

15. Chan AT, Lo YM, Zee B, et al. Plasma Epstein-Barr virus DNA and residual disease after radiotherapy for undifferentiated nasopharyngeal carcinoma. J Natl Cancer Inst 2002;94:1614-1619.

16. Lin JC, Wang WY, Chen KY, et al. Quantification of plasma Epstein-Barr virus DNA in patients with advanced nasopharyngeal carcinoma. N Engl J Med 2004;350:2461-2470

17. Al-Sarraf M, LeBlanc M, Giri PG, et al. Chemoradiotherapy versus radiotherapy in patients with advanced nasopharyngeal cancer: phase III randomized Intergroup study 0099. J Clin Oncol 1998;16:1310-1317.

18. Bossi P, Orlandi E, Bergamini C, et al. Docetaxel, cisplatin and 5-fluorouracil-based induction chemotherapy followed by intensitymodulated radiotherapy concurrent with cisplatin in locally advanced EBV-related nasopharyngeal cancer. Ann Oncol 2011;22:2495-2500.

19. Sun X, Su S, Chen C, et al. Long-term outcomes of intensity-modulated radiotherapy for 868 patients with nasopharyngeal carcinoma: an analysis of survival and treatment toxicities. Radiother Oncol 2014;110:398-403.
20. Lin S, Lu JJ, Han L, et al. Sequential chemotherapy and intensitymodulated radiation therapy in the management of locoregionally advanced nasopharyngeal carcinoma: experience of 370 consecutive cases. BMC Cancer 2010;10:39.

21. An $X$, Wang FH, Ding PR, et al. Plasma Epstein-Barr virus DNA level strongly predicts survival in metastatic/recurrent nasopharyngeal carcinoma treated with palliative chemotherapy. Cancer 2011;117:3750-3757.

22. Shao JY, Li YH, Gao HY, et al. Comparison of plasma Epstein-Barr virus (EBV) DNA levels and serum EBV immunoglobulin A/virus capsid antigen antibody titers in patients with nasopharyngeal carcinoma. Cancer 2004 100:1162-1170.

23. Leung SF, Zee B, Ma BB, et al. Plasma Epstein-Barr viral deoxyribonucleic acid quantitation complements tumor-node-metastasis staging prognostication in nasopharyngeal carcinoma. J Clin Oncol 2006;24:5414-5418.

24. Tang LQ, Chen QY, Fan W, et al. Prospective study of tailoring whole-body dual-modality $\left[{ }^{18} \mathrm{~F}\right]$ fluorodeoxyglucose positron emission tomography/ computed tomography with plasma Epstein-Barr virus DNA for detecting distant metastasis in endemic nasopharyngeal carcinoma at initial staging. J Clin Oncol 2013;31:2861-2869.

25. Baujat B, Audry H, Bourhis J, et al. Chemotherapy in locally advanced nasopharyngeal carcinoma: an individual patient data meta-analysis of eight randomized trials and 1753 patients. Int J Radiat Oncol Biol Phys 2006;64:47-56.

26. Pfister DG, Spencer S, Adelstein D, et al. NCCN Clinical Practice Guidelines in Oncology: Head and Neck Cancers. Version 1.2019. Accessed April 29, 2019. To view the most recent version, visit NCCN.org.

27. Lee AW, Tung SY, Ngan RK, et al. Factors contributing to the efficacy of concurrent-adjuvant chemotherapy for locoregionally advanced nasopharyngeal carcinoma: combined analyses of NPC-9901 and NPC-9902 trials. Eur J Cancer 2011:47:656-666.

28. Twu CW, Wang WY, Chen CC, et al. Metronomic adjuvant chemotherapy improves treatment outcome in nasopharyngeal carcinoma patients with postradiation persistently detectable plasma Epstein-Barr virus deoxyribonucleic acid. Int J Radiat Oncol Biol Phys 2014;89:21-29.

29. Chen L, Hu CS, Chen XZ, et al. Concurrent chemoradiotherapy plus adjuvant chemotherapy versus concurrent chemoradiotherapy alone in patients with locoregionally advanced nasopharyngeal carcinoma: a phase 3 multicentre randomised controlled trial. Lancet Oncol 2012;13:163-171.

30. Wee J, Tan EH, Tai BC, et al. Randomized trial of radiotherapy versus concurrent chemoradiotherapy followed by adjuvant chemotherapy in patients with American Joint Committee on Cancer/International Union Against Cancer stage III and IV nasopharyngeal cancer of the endemic variety. J Clin Oncol 2005;23:6730-6738.

31. Lee AW, Tung SY, Chua DT, et al. Randomized trial of radiotherapy plus concurrent-adjuvant chemotherapy vs radiotherapy alone for regionally advanced nasopharyngeal carcinoma. J Natl Cancer Inst 2010;102:1188-1198.

32. Chen $Y$, Liu MZ, Liang SB, et al. Preliminary results of a prospective randomized trial comparing concurrent chemoradiotherapy plus adjuvant chemotherapy with radiotherapy alone in patients with locoregionally advanced nasopharyngeal carcinoma in endemic regions of china. Int J Radiat Oncol Biol Phys 2008;71:1356-1364.

33. Sun Y, Li WF, Chen NY, et al. Induction chemotherapy plus concurrent chemoradiotherapy versus concurrent chemoradiotherapy alone in locoregionally advanced nasopharyngeal carcinoma: a phase 3 , multicentre, randomised controlled trial. Lancet Oncol 2016;17:1509-1520.

34. Ribassin-Majed L, Marguet S, Lee AWM, et al. What is the best treatment of locally advanced nasopharyngeal carcinoma? An individual patient data network meta-analysis. J Clin Oncol 2017;35:498-505.

35. Nasr HB, Chahed K, Bouaouina N, et al. Functional vascular endothelial growth factor $-2578 \mathrm{C} / \mathrm{A}$ polymorphism in relation to nasopharyngeal carcinoma risk and tumor progression. Clin Chim Acta 2008;395:124-129.

36. OuYang PY, Zhang $L N$, Lan $X W$, et al. The significant survival advantage of female sex in nasopharyngeal carcinoma: a propensity-matched analysis. Br J Cancer 2015:112:1554-1561.

37. Xiao G, Cao Y, Qiu X, et al. Influence of gender and age on the survival of patients with nasopharyngeal carcinoma. BMC Cancer 2013;13:226.

See JNCCN.org for supplemental online content. 
Supplemental online content for:

\section{Neoadjuvant or Adjuvant Chemotherapy Plus Concurrent CRT Versus Concurrent CRT Alone in the Treatment of Nasopharyngeal Carcinoma: A Study Based on EBV DNA}

Li-Ting Liu, MD; Qiu-Yan Chen, MD; Lin-Quan Tang, MD; Shan-Shan Guo, MD; Ling Guo, MD, PhD; Hao-Yuan Mo, MD, PhD; Yang Li, MD; Qing-Nan Tang, MD; Xue-Song Sun, MD; Yu-Jing Liang, MD; Chong Zhao, MD, PhD; Xiang Guo, MD, PhD; Chao-Nan Qian, MD, PhD; Mu-Sheng Zeng, PhD; Jin-Xin Bei, PhD; Ming-Huang Hong, MD, PhD; Jian-Yong Shao, MD, PhD; Ying Sun, MD, PhD; Jun Ma, MD, PhD; and Hai-Qiang Mai, MD, PhD

J Natl Compr Canc Netw 2019;17(6):703-710

eFigure 1: Comparison of CCRT Alone Versus CCRT + NACT or ACT

eFigure 2: Comparison of Different NACT Regimens

eFigure 3: Comparison of Different Risk Groups

eFigure 4: Comparison of Different Treatment Methods

eTable 1: Comparison of Cumulative Survival Rates Among Treatment Groups

eTable 2: Patient Characteristics Stratified by Risk Group

eAppendix 1: Design of the Intensity-Modulated Radiotherapy Plan 
A

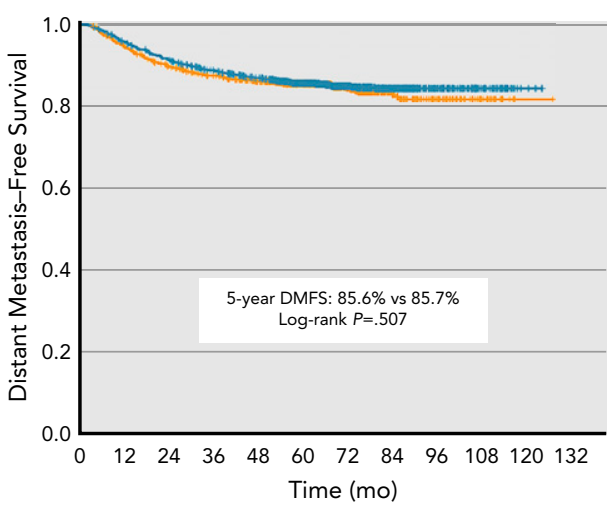

$\begin{array}{lllllllllllll}\text { C CCRT } & 970 & 918 & 857 & 809 & 759 & 571 & 328 & 149 & 81 & 31 & 1 & 0\end{array}$

— CCRT + NACT/ 1,293 1,233 1,174 1,1081,045 $926 \quad 585310 \quad 157 \quad 71 \quad 1 \quad 0$ $A C T$
B

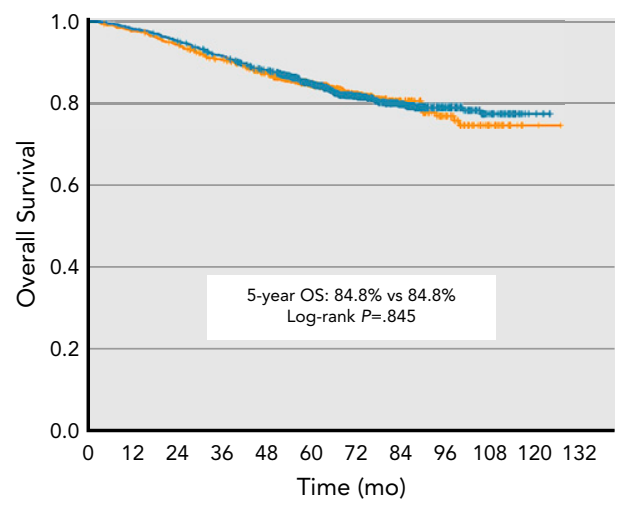

$\begin{array}{lllllllllllll}\text { CCRT } & 970 & 950 & 914 & 862 & 801 & 599 & 340 & 158 & 85 & 33 & 2 & 0\end{array}$

CCRT + NACT/ 1,2931,271 1,232 1,1731,102 $967604 \quad 322162 \quad 73 \quad 7 \quad 6$

\section{C}

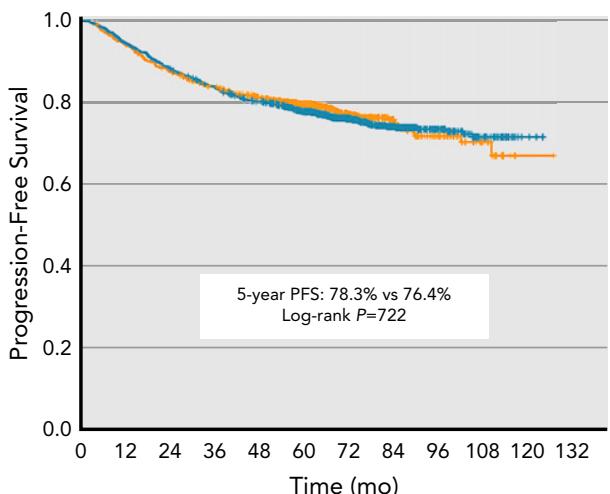

$\begin{array}{lllllllllllll}\text { CCRT } & 970 & 913 & 843 & 785 & 731 & 548 & 311 & 142 & 76 & 30 & 1 & 0\end{array}$

$\begin{array}{llllllllll}\text { CCRT + NACT/ } & 1,2931,2211,1371,062 & 995 & 877 & 554 & 290 & 148 & 66 & 7 & 0 \\ \text { ACT }\end{array}$

eFigure 1. CCRT alone versus CCRT + NACT or ACT with regard to rates of (A) distant metastasis-free survival, (B) overall survival, and (C) progression-free survival.

Abbreviations: ACT, adjuvant chemotherapy; CCRT, concurrent chemoradiotherapy; NACT, neoadjuvant chemotherapy. 


\section{2 - Liu et al}

A

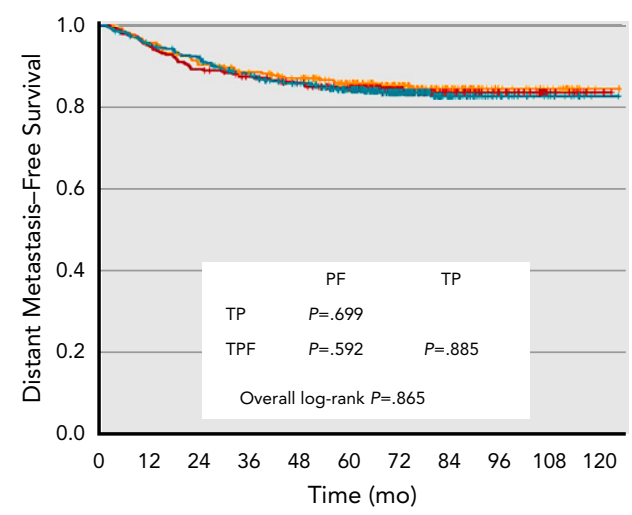

Number at risk

$\begin{array}{llllllllllll}\text { PF } & 287 & 273 & 259 & 243 & 229 & 197 & 130 & 71 & 32 & 22 & 2\end{array}$

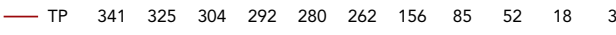

$\begin{array}{llllllllllll}-\mathrm{TPF} & 445 & 422 & 406 & 378 & 351 & 310 & 170 & 68 & 25 & 12\end{array}$

\section{C}

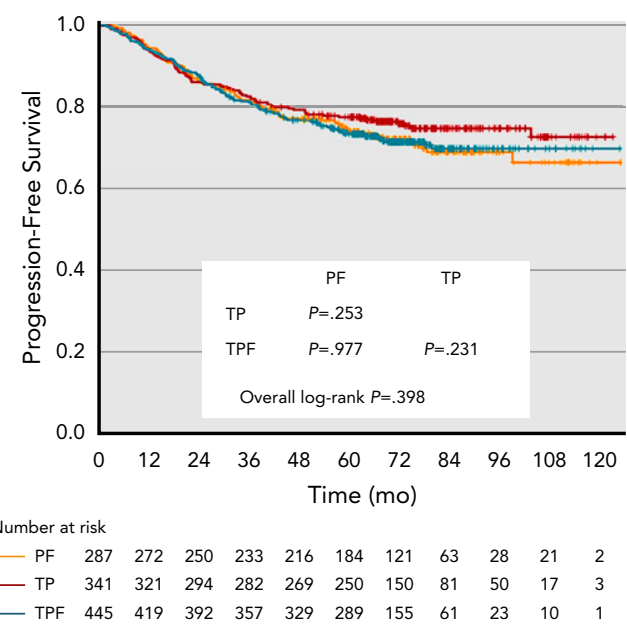

B

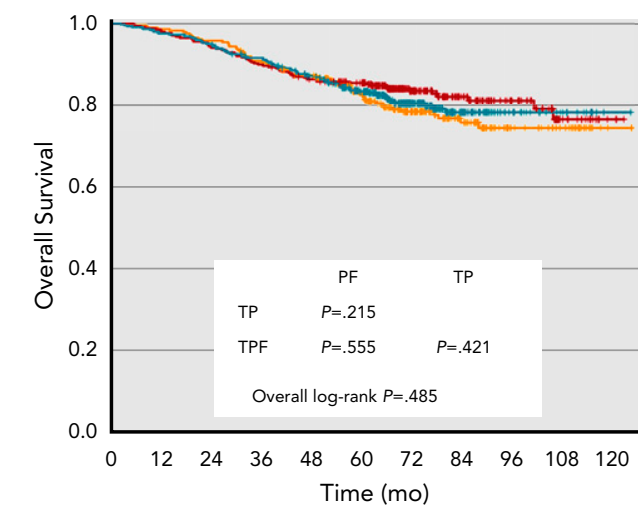

Number at risk

$\begin{array}{llllllllllll}-\mathrm{PF} & 287 & 283 & 275 & 259 & 243 & 204 & 133 & 74 & 33 & 23 & 2\end{array}$

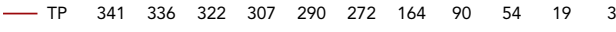

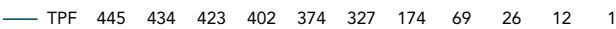

survival.

Abbreviations: PF, cisplatin $\left(80 \mathrm{mg} / \mathrm{m}^{2}\right.$, day 1) with 5-fluorouracil $\left(800-1,000 \mathrm{mg} / \mathrm{m}^{2}, 96\right.$ hours of continuous intravenous infusion); TP, cisplatin with docetaxel

$\left(75 \mathrm{mg} / \mathrm{m}^{2}\right.$, day 1); TPF, cisplatin $\left(75 \mathrm{mg} / \mathrm{m}^{2}\right.$, day 1$)$ and docetaxel $\left(75 \mathrm{mg} / \mathrm{m}^{2}\right.$, day 1$)$ with 5 -fluorouracil $\left(750 \mathrm{mg} / \mathrm{m}^{2}, 96\right.$ hours of continuous intravenous infusion). 
A

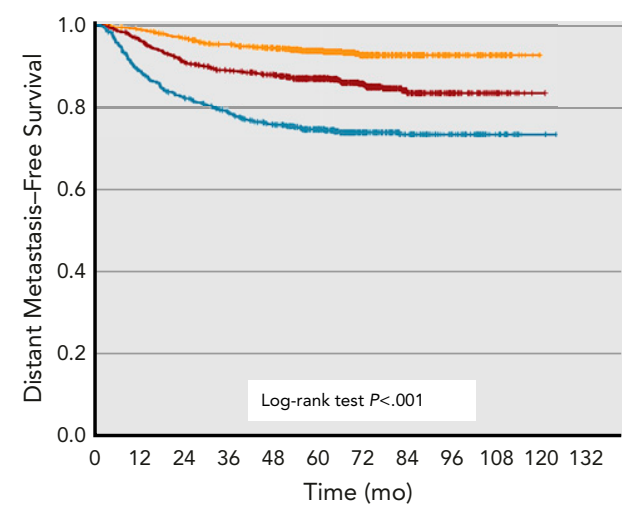

Number at risk

- Low-risk group Intermediate-
risk group

- High-risk group $\begin{array}{llllllllllll}818 & 808 & 783 & 743 & 705 & 578 & 322 & 159 & 87 & 39 & 3 & 0\end{array}$ $\begin{array}{llllllllllll}818 & 788 & 740 & 701 & 670 & 558 & 362 & 166 & 77 & 32 & 2 & 0\end{array}$

$\begin{array}{llllllllllll}627 & 555 & 508 & 473 & 429 & 361 & 229 & 134 & 74 & 31 & 3 & 0\end{array}$
B

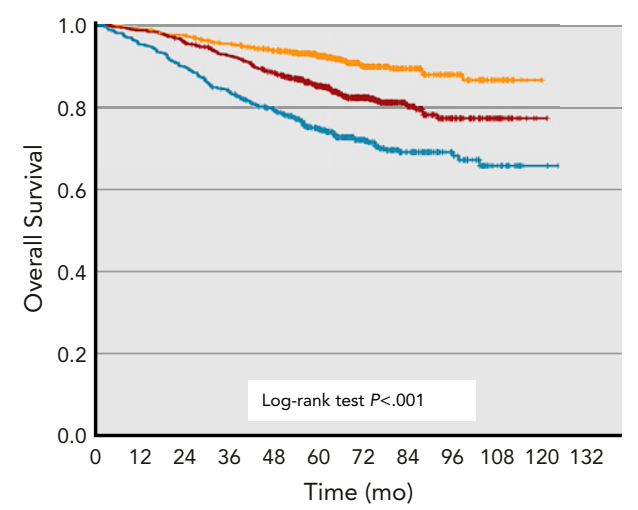

Number at risk

- Low-risk group Intermediate-
risk group

- High-risk group $\begin{array}{llllllllllll}818 & 812 & 796 & 763 & 726 & 598 & 330 & 165 & 91 & 40 & 3 & 0\end{array}$ $\begin{array}{llllllllllll}818 & 808 & 788 & 750 & 706 & 585 & 374 & 176 & 80 & 34 & 3 & 0\end{array}$

$\begin{array}{llllllllllll}627 & 601 & 562 & 522 & 471 & 383 & 240 & 139 & 76 & 32 & 3 & 0\end{array}$

C

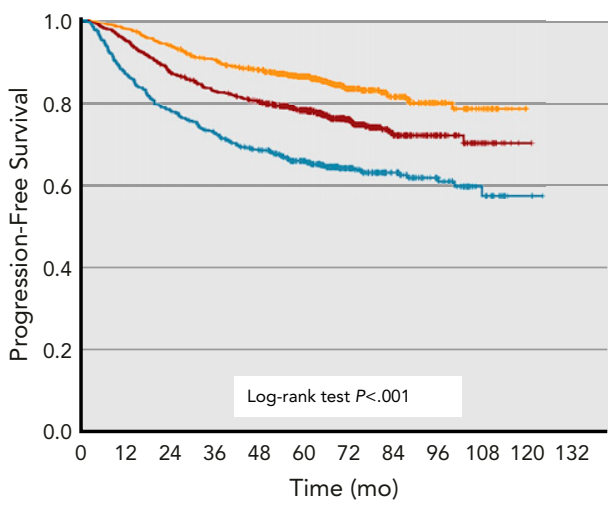

Number at risk

Low-risk group

Intermediate-

risk group

_ High-risk group

$\begin{array}{llllllllllll}818 & 803 & 770 & 724 & 680 & 556 & 305 & 152 & 82 & 38 & 3 & 0\end{array}$

$\begin{array}{llllllllllll}818 & 783 & 722 & 672 & 639 & 529 & 348 & 157 & 73 & 29 & 2 & 0\end{array}$

$\begin{array}{llllllllllll}627 & 548 & 488 & 451 & 407 & 340 & 212 & 123 & 68 & 29 & 3 & 0\end{array}$

eFigure 3. Comparison of different risk groups with regard to rates of (A) distant metastasis-free survival, (B) overall survival, and (C) progressionfree survival. 


\section{4 - Liu et al}

A

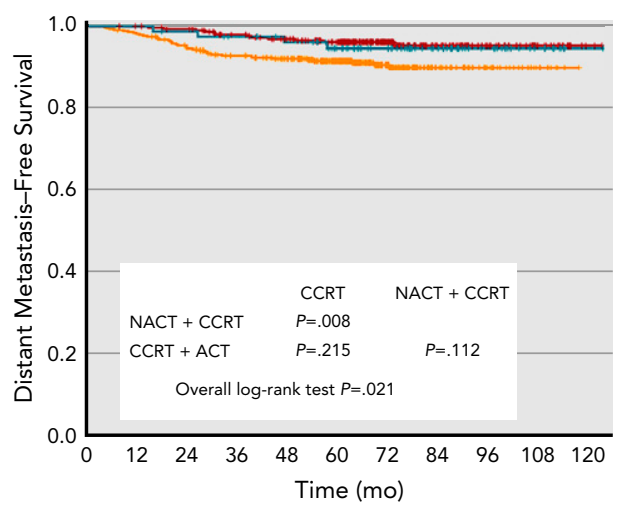

Number at risk

$\begin{array}{llllllllllll}\text { - CCRT } & 435 & 427 & 409 & 387 & 366 & 272 & 140 & 54 & 25 & 9 & 0\end{array}$ $\begin{array}{lrrrrrrrrrrr}- \text { NACT + CCRT } & 303 & 301 & 296 & 281 & 268 & 244 & 131 & 70 & 41 & 21 & 2\end{array}$

\section{C}

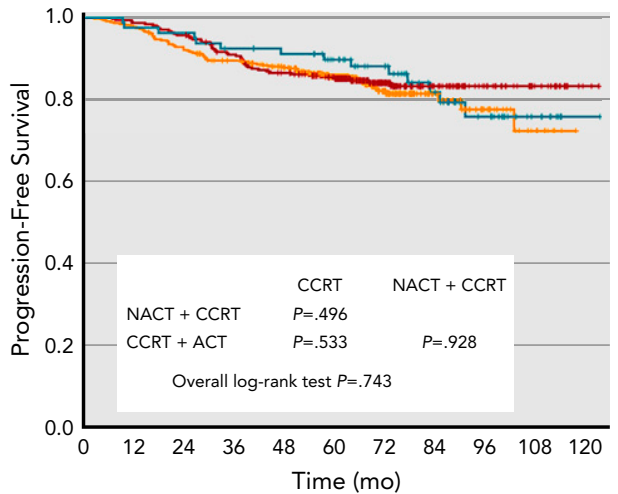

Number at risk

$\begin{array}{llllllllllll}\text { CCRT } & 435 & 426 & 403 & 380 & 356 & 263 & 132 & 52 & 24 & 9 & 0\end{array}$

$\begin{array}{llllllllllll}-\mathrm{NACT}+\mathrm{CCRT} & 303 & 299 & 290 & 271 & 254 & 231 & 122 & 65 & 37 & 20 & 2\end{array}$

$\begin{array}{lrrrrrrrrrrr}-\mathrm{CCRT}+\mathrm{ACT} & 80 & 78 & 77 & 73 & 70 & 62 & 51 & 35 & 21 & 9 & 1\end{array}$

\section{E}

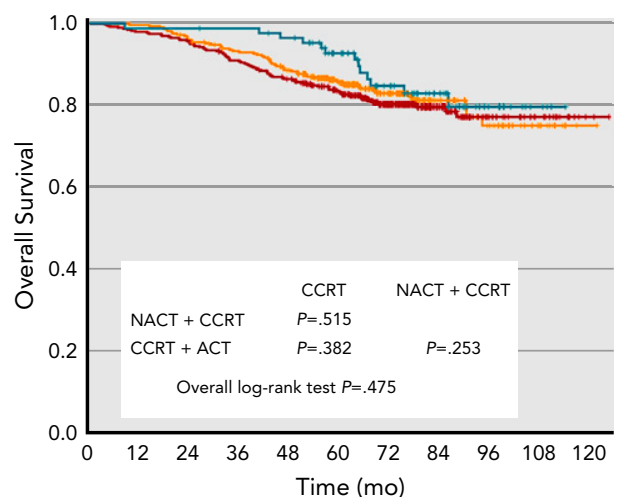

Number at risk

$\begin{array}{llllllllllll}\text { C CCRT } & 330 & 329 & 318 & 302 & 282 & 219 & 130 & 60 & 35 & 14 & 1\end{array}$

$\begin{array}{llllllllllll}-\mathrm{NACT}+\mathrm{CCRT} & 401 & 393 & 384 & 363 & 342 & 300 & 195 & 85 & 32 & 16 & 2\end{array}$
B

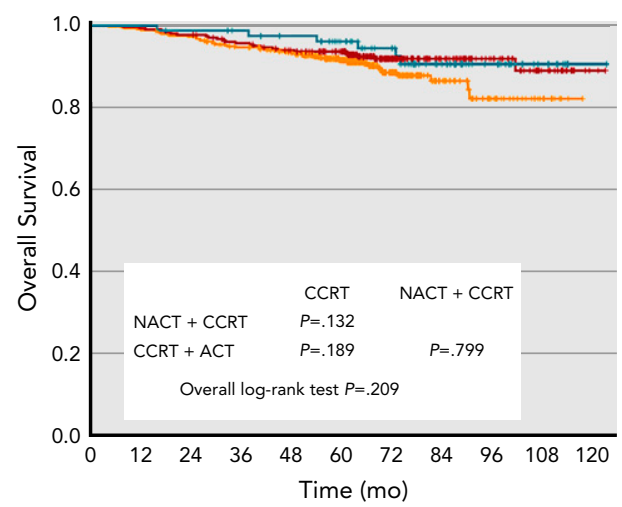

Number at risk

$\begin{array}{llllllllllll}\text { - CCRT } & 435 & 431 & 422 & 402 & 380 & 283 & 143 & 56 & 10 & 0 & 0\end{array}$

$\begin{array}{lllllllllllll}-N A C T & + \text { CCRT } & 303 & 301 & 296 & 285 & 274 & 251 & 134 & 73 & 43 & 21 & 0\end{array}$

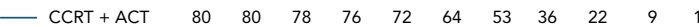

\section{D}

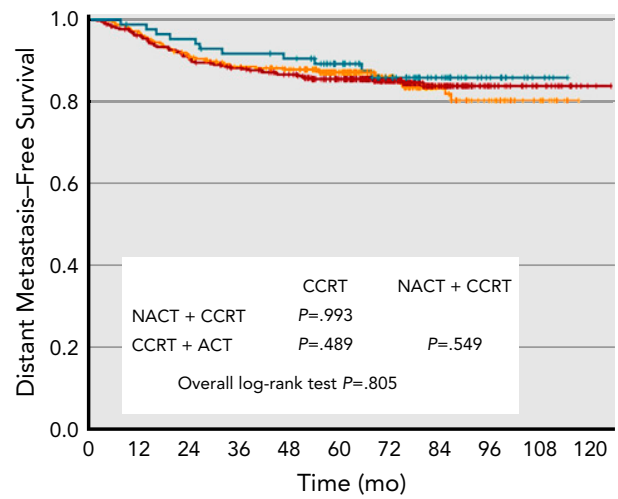

Number at risk

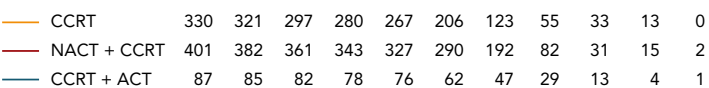

\section{$\mathbf{F}$}

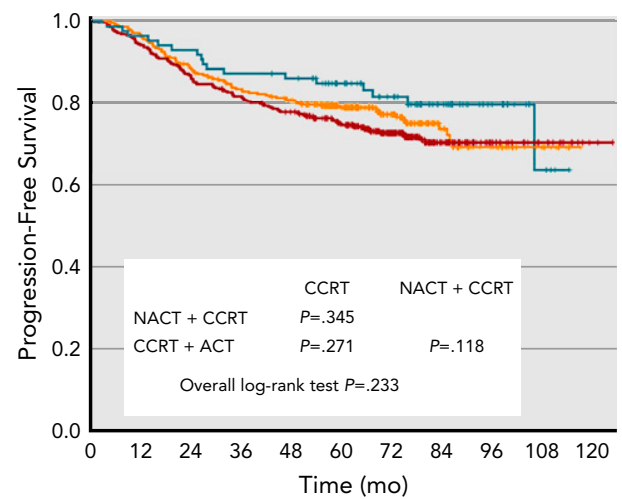

Number at risk

$\begin{array}{llllllllllll}\text { C CRT } & 330 & 320 & 292 & 270 & 257 & 199 & 121 & 53 & 31 & 12 & 0\end{array}$

$\begin{array}{llllllllllll}-\mathrm{NACT}+\text { CCRT } & 401 & 379 & 349 & 326 & 308 & 270 & 180 & 75 & 29 & 13 & 2\end{array}$

$\begin{array}{llllllrrrrrr}-\mathrm{CCRT}+\mathrm{ACT} & 87 & 84 & 81 & 76 & 74 & 60 & 47 & 29 & 13 & 4 & 0\end{array}$

(continued on next page)

eFigure 4. Comparison of the probablility of different treatment methods in the $(A, B, C)$ low-risk group, $(D, E, F)$ intermediate-risk group, and $(G, H, I)$ high-risk group with regard to distant metastasis-free survival, overall survival, and progression-free survival rates.

Abbreviations: ACT, adjuvant chemotherapy; CCRT, concurrent chemoradiotherapy; NACT, neoadjuvant chemotherapy. 
(continued)

\section{G}

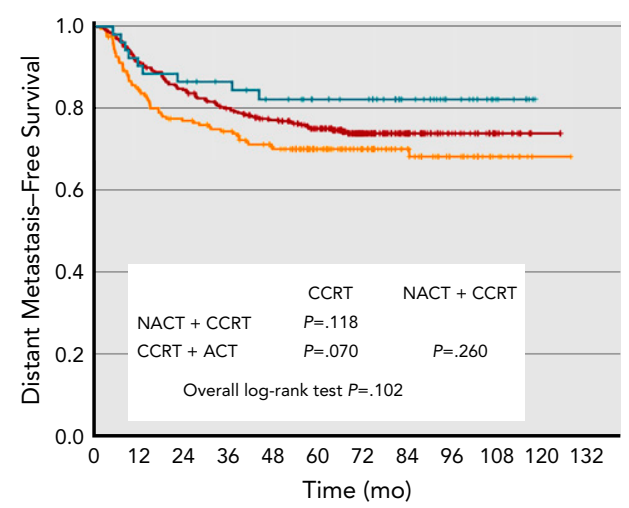

Number at risk

$\begin{array}{llllllllllllll}\text { CCRT } & 205 & 170 & 151 & 142 & 126 & 93 & 65 & 40 & 23 & 9 & 1 & 0\end{array}$

$\begin{array}{lllllllllllllll}-\mathrm{NACT}+\mathrm{CCRT} & 369 & 337 & 312 & 289 & 265 & 235 & 133 & 72 & 37 & 15 & 2 & 0\end{array}$

$\begin{array}{lllllllllllll}-\mathrm{CCRT}+\mathrm{ACT} & 53 & 48 & 45 & 42 & 38 & 33 & 31 & 22 & 14 & 6 & 0 & 0\end{array}$

\section{$\mathbf{H}$}

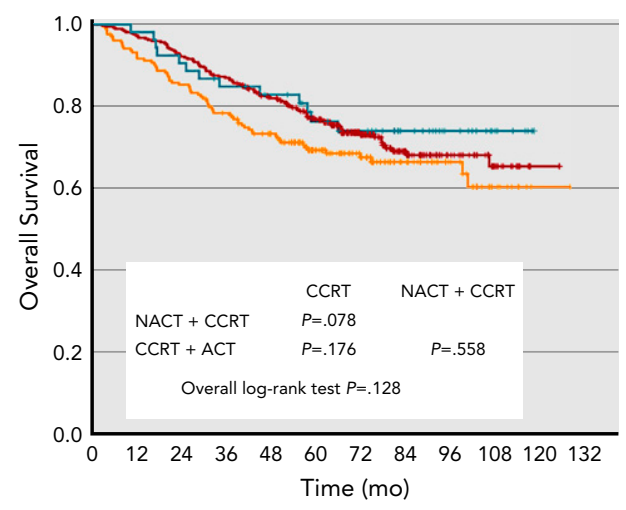

Number at risk

$\begin{array}{lllllllllllll}\text { CCRT } & 205 & 190 & 174 & 158 & 139 & 97 & 67 & 42 & 24 & 9 & 1 & 0\end{array}$

$\begin{array}{lllllllllllll}\text { — NACT + CCRT } & 369 & 359 & 340 & 320 & 291 & 252 & 142 & 75 & 38 & 17 & 2 & 0\end{array}$

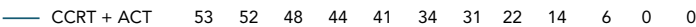

\section{I}

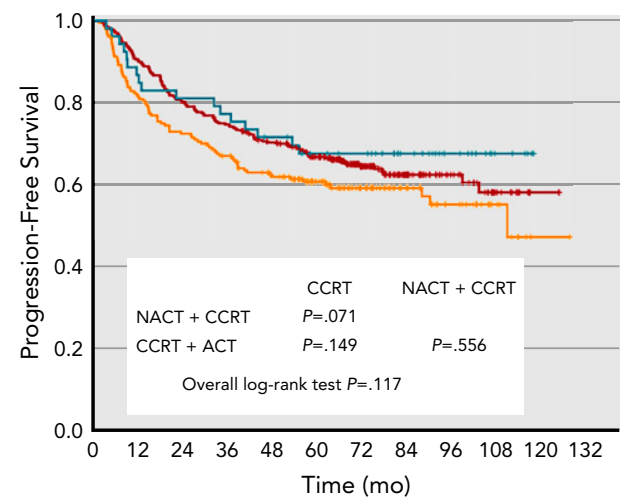

Number at risk

\begin{tabular}{lrrrrrrrrrrrr} 
- CCRT & 205 & 167 & 148 & 135 & 118 & 86 & 58 & 37 & 21 & 9 & 1 & 0 \\
\hline NACT + CCRT & 369 & 334 & 297 & 275 & 252 & 222 & 124 & 65 & 35 & 15 & 2 & 0 \\
CCRT + ACT & 53 & 47 & 43 & 41 & 37 & 32 & 30 & 21 & 13 & 5 & 0 & 0
\end{tabular}

eFigure 4. Comparison of the probablility of different treatment methods in the $(A, B, C)$ low-risk group, $(D, E, F)$ intermediate-risk group, and $(G, H, I)$ high-risk group with regard to distant metastasis-free survival, overall survival, and progression-free survival rates.

Abbreviations: ACT, adjuvant chemotherapy; CCRT, concurrent chemoradiotherapy; NACT, neoadjuvant chemotherapy. 
6 - Liu et al

eTable 1. Comparison of Cumulative Survival Rates Among Treatment Groups

\begin{tabular}{|c|c|c|c|c|c|c|c|c|}
\hline Treatment Group & $\mathbf{n}$ & $\%$ & 5-Year DMFS (95\% Cl) & $P$ Value & 5-Year OS $(95 \% \mathrm{Cl})$ & $P$ Value & 5-Year PFS $(95 \% \mathrm{Cl})$ & $P$ Value \\
\hline & & & & .179 & & .184 & & .153 \\
\hline CCRT & 970 & 42.9 & $85.6 \%(83.4 \%-87.8 \%)$ & & $84.8 \%(82.4 \%-87.2 \%)$ & & $78.3 \%(75.8 \%-80.8 \%)$ & \\
\hline NACT + CCRT & 1,073 & 47.4 & $85.0 \%(82.8 \%-87.2 \%)$ & & $84.0 \%(81.8 \%-86.2 \%)$ & & $75.1 \%(72.6 \%-77.6 \%)$ & \\
\hline $\mathrm{CCRT}+\mathrm{ACT}$ & 220 & 9.7 & $89.7 \%$ (85.6\%-93.8\%) & & $90.0 \%(85.9 \%-94.1 \%)$ & & $82.6 \%(77.5 \%-87.7 \%)$ & \\
\hline
\end{tabular}

Abbreviations: ACT, adjuvant chemotherapy; CCRT, concurrent chemoradiotherapy; DMFS, distant metastasis-free survival; NACT, neoadjuvant chemotherapy; OS, overall survival; PFS, progression-free survival. 
Liu et al - 7

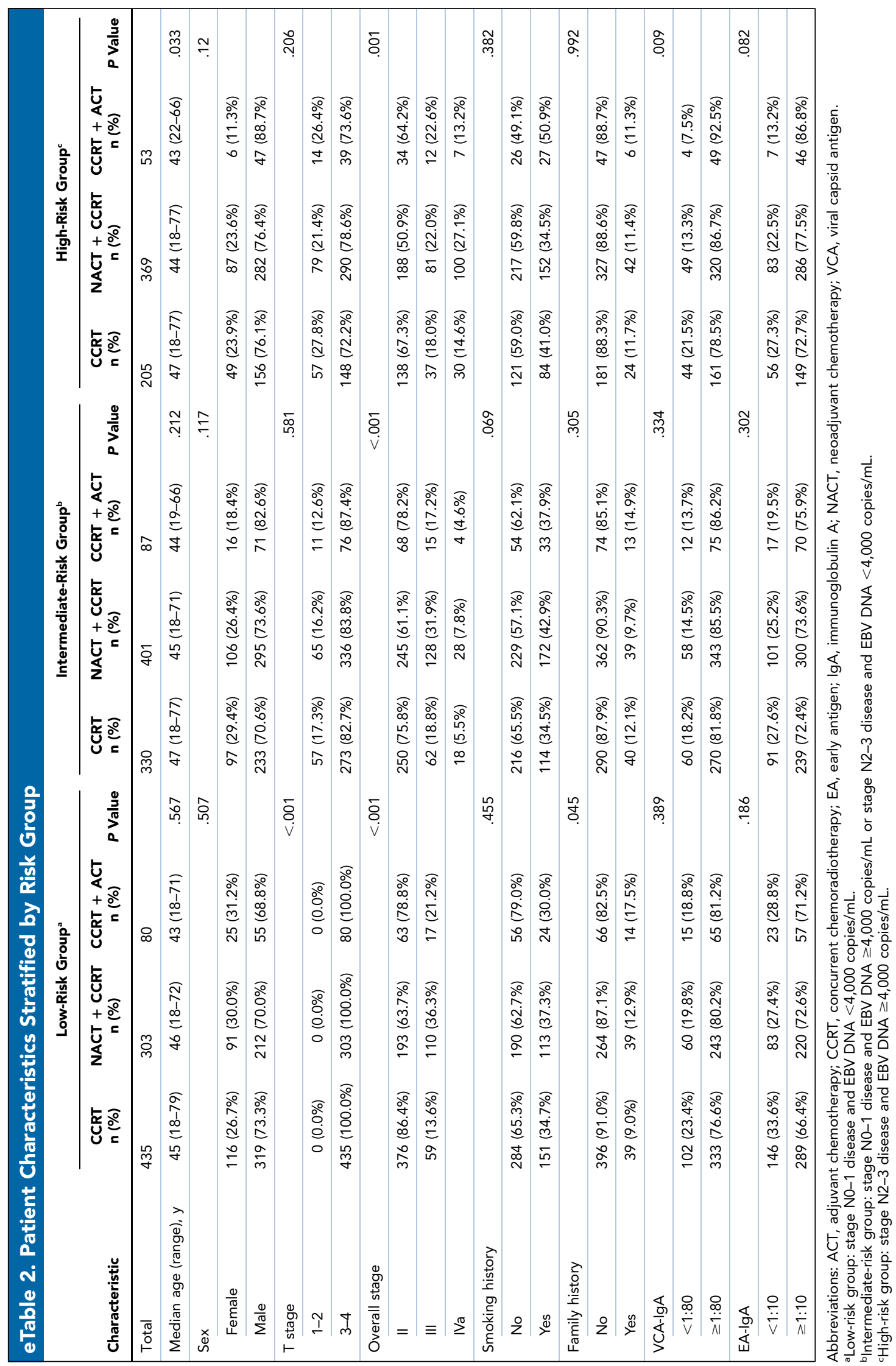




\section{eAppendix 1. Design of the Intensity-Modulated Radiotherapy Plan}

All patients were immobilized in the supine position with a head, neck, and shoulder thermoplastic mask. Two sets of images, with and without contrast, were obtained from the CT simulator for treatment planning. All patients were scanned with serial 3-mm slices from the vertex through the clavicles. Inverse intensity-modulated radiotherapy planning was performed using CORVUS version 3.0 (Best NOMOS), and a MIMiC multileaf collimator (NOMOS) was used for planning and treatment.

The primary and nodal gross tumor volumes (GTV) included all gross diseases visualized by CT and/or MRI. The highrisk clinical tumor volume (CTV-1) included GTV plus a 5- to 10-mm margin and encompassed the entire nasopharyngeal mucosa plus 5-mm submucosal volume. CTV-2 was designed for potentially involved regions included in the nasopharyngeal cavity (limited only to the posterior part of the nasal cavity), maxillary sinus (limited to $5 \mathrm{~mm}$ anterior to the posterior nasal aperture and maxillary mucosa), pterygopalatine fossa, posterior ethmoid sinus, parapharyngeal space, skull base, anterior third of the clivus and cervical vertebra, inferior sphenoid sinus, and cavernous sinus, and it included the retropharyngeal lymph node regions from the base of the skull to the cranial edge of the second cervical vertebra. CTV of the neck nodal regions included levels II, III, IV, and V, which were outlined according to the recommendation by the RTOG/EORTC CTV delineation protocol for head and neck malignancies. The planning target volume (PTV) was created based on each volume with an additional 3-mm margin, allowing for setup variability. Critical normal structures, including the brainstem, spinal cord, parotid glands, optic nerves, chiasm, lens, eyeballs, temporal lobes, temporomandibular joints, mandible, and hypophysis, were contoured and set as organs at risk during optimization.

The dose-volume histograms of the treatment targets and critical normal structures were evaluated. The prescribed dose was 68 to 70 Gy to the PTV of GTV of nasopharynx, 60 Gy to PTV-1, 54 Gy to PTV-2, and 60 to 70 Gy to PTV of the GTV of lymph nodes in 30 to 33 fractions. For GTV and CTV, the target volumes receiving 95\% of the prescribed dose were used to reflect the target coverage, and the maximal, minimal, and mean doses delivered to the target volumes were also calculated. For critical organs with functional subunits organized in series, such as the brainstem, optic chiasm, and optic nerves, the dose delivered to $5 \%$ of the volumes was examined. For critical organs with functional subunits organized in parallel, the dose delivered to $33 \%$ of the volumes was evaluated. The dose distribution was also examined slice by slice on the CT image. 